\title{
SENTIDOS SOBRE A PRÁTICA GRUPAL NO CONTEXTO DE SAÚDE PÚBLICA
}

\author{
Emerson Fernando Rasera* \\ Rita Martins Godoy Rocha"
}

\begin{abstract}
RESUMO. Considerando-se que a atuação dos psicólogos por meio das práticas grupais tem sido uma alternativa qualificada dos serviços em saúde pública, o objetivo desta pesquisa foi descrever os sentidos de práticas grupais identificados em dezoito entrevistas semiestruturadas com psicólogos atuantes na saúde pública em Uberlândia - MG. A análise do discurso, baseada na perspectiva do construcionismo social, permitiu identificar quatro repertórios interpretativos: grupo como espaço coletivo, como alternativa para a demanda, como proposta mediadora e como estranhamento. O uso dos repertórios possibilitou legitimar a prática grupal de diferentes maneiras, porém o predomínio de um viés clínico-individualista na fala dos entrevistados sobre as práticas grupais dificultou uma descrição voltada às equipes e comunidades e sensível ao nível de atenção em saúde. Prevalece, assim, a necessidade de novas construções sobre o dizer/fazer das práticas grupais na saúde brasileira.
\end{abstract}

Palavras-chave: Práticas grupais; psicologia; saúde pública.

\section{THE MEANINGS OF GROUP WORK IN THE PUBLIC HEALTH CONTEXT}

\begin{abstract}
Group work has been considered an alternative of psychological intervention in the public health context. The objective of this research was to describe the meanings of group practice present in eighteen semistructured interviews with psychologists that work in the public health context in Uberlândia-MG. The discourse analysis, based on Social Constructionism perspective, allowed the identification of four interpretative repertoires used to describe group work: group as a collective space; as an alternative to the demand; as a mediating activity; and as strangeness. The use of the repertoires legitimized group work in different ways. However, the predominance of a clinical-individualist bias on the interviewees' speech hasn't allowed a description of group practice designed to teams and communities and sensitive to the level of health attention. Thus, it is necessary to construct new ways of saying/doing group work in the Brazilian health context.
\end{abstract}

Key words: Group work; psychology; public health.

\section{SENTIDOS SOBRE LA PRÁCTICA GRUPAL EN EL CONTEXTO DE SALUD PÚBLICA}

RESUMEN. Considerando que actuación de los psicólogos a través de las prácticas grupales es una alternativa cualificada de los servicios en salud pública, el objetivo de esa investigación fue describir los sentidos sobre prácticas grupales identificados en dieciocho entrevistas semiestructuradas con psicólogos actuantes en la salud pública en Uberlândia-MG. El análisis del discurso realizada permitió identificar cuatro repertorios interpretativos: grupo como espacio colectivo; como alternativa para la demanda; como propuesta mediadora; y como extrañamiento. El uso de los repertorios permitió legitimar la práctica grupal de diferentes maneras. Con todo, el predominio de un sesgo clínico-individualista dificultó una descripción dirigida a los equipos y comunidades, y sensible al nivel de atención en salud. Prevalece, así, la necesidad de nuevas construcciones sobre el decir/hacer de las prácticas grupales en la salud brasileña.

Palabras-clave: Prácticas grupales; psicologia; salud pública.

\footnotetext{
* Doutor em Psicologia. Professor Adjunto da Universidade Federal de Uberlândia.
}

\# Mestrado em Psicologia em Psicologia na Universidade Federal de Uberlândia. 


\section{A INSERÇÃO DO PSICÓLOGO E AS PRÁTICAS GRUPAIS NA SAÚDE PÚBLICA}

As atuais conjunturas sociais e profissionais demandam uma atuação do psicólogo em contextos mais amplos, diferentes da clínica privada, que seja desvinculado de um modelo estritamente tecnicista e compreenda a Psicologia aliada ao compromisso social de uma ciência a serviço dos interesses da maioria da sociedade (Bock, 2003). No campo da saúde pública essa demanda tem se tornado ainda mais relevante.

Desde a década de 80, vários estudos têm apontado os impasses da inserção do psicólogo e das práticas psicológicas no contexto de saúde pública no Brasil (Benevides, 2005; Dimenstein, 2000; Silva 1992; Spink, Bernardes \& Menegon, 2006). De forma geral, estes estudos mostram as dificuldades que acompanham a inserção do psicólogo nesse contexto, em vista de seu despreparo profissional e da escassez de estágios e discussões em saúde pública na graduação em Psicologia, e o predomínio de uma prática clínica descontextualizada e baseada no consultório particular, a qual não reconhece as especificidades de outras populações e locais de atuação.

Em um estudo recente sobre a atuação do psicólogo no contexto de saúde pública em uma cidade mineira, Goya e Rasera (2007) reafirmam tais análises, apontando a falta de formação dos profissionais para o trabalho no serviço público, o predomínio de um discurso simplificado e estereotipado sobre saúde, bem como o desconhecimento dos profissionais sobre os princípios do SUS. Observaram ainda a ausência de atividades que se relacionem à promoção de saúde e prevenção, bem como a falta de identificação do psicólogo como um profissional de saúde, prevalecendo a dicotomia saúde e saúde mental. Essa dicotomia é produzida pela ênfase que muitas vezes o psicólogo confere a uma atuação baseada no tratamento de transtornos psíquicos, a qual não valoriza o cuidado de outros problemas de saúde, nem por meio do apoio nem mediante orientação psicológica, dificultando o trabalho como membro da equipe de saúde.

A tentativa de produzir um novo modo de atuação em saúde pública, voltado às necessidades e características da população atendida, concretizou-se, muitas vezes, por meio da aposta na utilização das práticas grupais. Esse investimento está relacionado às características do trabalho em grupo que se mostram sensíveis à cultura, ao vocabulário e à linguagem de seus membros, valorizando o contexto social. O grupo representa, ainda, a marca do coletivo que permite o reconhecimento do sofrimento compartilhado, ampliando as formas de entendimento e significação do processo saúde e doença, e potencializa a organização e ação conjuntas.

As práticas grupais, neste sentido, estão em conformidade com o preconizado pelo SUS e seus princípios de universalidade do acesso, integralidade da atenção e controle social, pois podem contribuir para a democratização do acesso à saúde no país, permitindo a participação da comunidade em sua atenção integral de acordo com suas necessidades específicas e a variabilidade de crenças e costumes e na própria gestão dos serviços.

Diferentes formas de atuação em grupo também têm recebido atenção pela Psicologia e crescem em campos da Psicologia Social Comunitária, conforme observamos no trabalho de Martins (2003), que ressalta a importância de uma atuação psicossocial em que o papel das relações de poder no cotidiano das pessoas é enfatizado, e consequentemente, o grupo atua como forma propícia para que essas relações diárias sejam percebidas, auxiliadas pela história e contexto partilhados por seus membros.

Não obstante, as condições de implementação e funcionamento destas práticas, muitas vezes vinculadas à burocratização da prática grupal, que a reconhece apenas como forma economicamente eficiente de responder à grande demanda, aliadas às dificuldades da formação profissional dos psicólogos, trouxeram inúmeros obstáculos que geraram diversas reflexões críticas.

Bezerra (1987) aponta que “(...) quando abordam terapias de grupo, parece por vezes que já não se veem outras razões para elas que não a economia de tempo, as exigências de produtividade dos ambulatórios e a necessidade de diminuir as listas de espera" (p.162). Esse autor considera que a demanda é muito mais vasta que os recursos, mas questiona esta situação, enfatizando que antes de pensar por essa perspectiva econômica do grupo deve-se procurar entender o porquê da ampla procura pelo tratamento, ou ainda a razão das desistências nos encontros subseqüentes, e assim viabilizar recursos adequados para promover um bom atendimento.

Nos estudos de Molena (1999) sobre a prática grupal em saúde pública, os psicólogos entrevistados demonstraram falta de familiaridade com as técnicas grupais e com o papel do coordenador, bem como dificuldades em se vincular a um contexto que tradicionalmente não ocuparam, o qual os convida a participar, mas não promove discussões acerca de propostas viáveis para o serviço. 
Souza (1999), da mesma forma, reconhece a grande utilização do recurso grupal como forma de intervenção nas instituições públicas, mas entende que este vem aliado ao descaso para com a maneira como o trabalho é realizado e ao estranhamento do profissional sobre seu papel de coordenador do grupo.

No contexto das oficinas, Lancetti (1993) aponta as dificuldades que envolvem os grupos com atividades manuais, os quais precisam considerar a atuação para além do "fazer uma tarefa" e da reintegração social e enfatizar os desdobramentos gerados na realização desse trabalho e a produção subjetiva aí promovida.

$\mathrm{Na}$ atualidade persiste a dificuldade de implantar o atendimento grupal em saúde pública, a despeito da necessidade aí presente. Segundo levantamento realizado em 2006, junto a 346 psicólogos de todo o Brasil, sobre as práticas desenvolvidas na saúde pública, cerca de $10,4 \%$ dos profissionais entrevistados afirmam realizar atendimento em grupo e 3,3\%, as oficinas. Estes percentuais são muito inferiores ao dos que realizam atendimento individual, os quais chegam a $42,1 \%$ (Spink, Bernardes \& Menegon, 2006).

Entre as tentativas de compreender as dificuldades envolvidas na atuação do psicólogo em saúde, inclusive das práticas grupais, está o questionamento de uma "cultura psicológica" dada como universal que atribui a qualquer grupo, em qualquer contexto, uma linguagem intimista ou interrogativa e estabelece como atividade do psicólogo, enquanto trabalhador da saúde mental, apenas o tratamento psicopatológico.

Nessa reflexão emergem outras questões, tais como: quais são as particularidades culturais e psicológicas dessa população? Quais diferenças são significativas e incompatíveis entre os sentidos de doença e cura, de sua causa e seu tratamento? Como é visto o papel do coordenador no processo grupal? Como é a aceitação da oferta de tratamento grupal quando a busca da população é pelo atendimento individual? A resposta a tais questionamentos favoreceria a intervenção no grupo, valorizando esta modalidade terapêutica e as demandas do usuário, ao invés de utilizá-la como uma técnica já consolidada e de forma acrítica (Nascimento, Manzini \& Bocco, 2006).

Apesar desses estudos e das críticas aí presentes, ainda hoje persiste uma escassez de discussões acerca das práticas grupais em Psicologia no Brasil (já apontada anteriormente por Lo Bianco, Bastos, Nunes \& Silva, 1994) e nos contextos de saúde pública, especificamente.
Diante disso, consideramos a relevância de novos estudos sobre práticas grupais em saúde pública, reconhecendo ainda que a mudança nestes contextos convida a novas formas de atuar em grupo. É nessa perspectiva que se desenvolve o presente estudo, buscando contribuir com discussões que permitam compreender algumas das dinâmicas e contradições no processo de produção de sentidos sobre as práticas grupais construídos por psicólogos que atuam na saúde pública.

\section{OBJETIVO}

A presente pesquisa teve por objetivo descrever os sentidos das práticas grupais identificados em entrevistas com psicólogos que atuam no contexto de saúde pública da cidade de Uberlândia - MG.

\section{CONTEXTO DA PESQUISA}

O município de Uberlândia possui uma rede de serviços de saúde composta por oito Unidades Básicas de Saúde (UBS), quarenta e três unidades básicas de Saúde da Família (UBSF), oito unidades de Atendimento Integrado (UAI) e seis centros de Atenção Psicossocial (CAPS), divididos em quatro distritos sanitários. Conforme informativo da Secretaria Municipal de Saúde de Uberlândia (Secretaria Municipal de Saúde de Uberlândia, 2005), em relação às atividades previstas para o psicólogo nessas unidades temos: atendimento individual, atendimento em grupo (psicoterapia, grupos operativos, atividades de suporte social), visitas domiciliares e psicodiagnóstico. Os psicólogos estão inseridos em diferentes unidades de saúde, contabilizando cerca de 60 profissionais em toda a rede pública.

\section{Passos na construção e análise do corpus}

Foram realizadas entrevistas semiestruturadas junto a 18 psicólogos atuantes no Programa de Saúde Mental da Secretaria de Saúde da Prefeitura Municipal de Uberlândia, compreendendo um profissional de UBS, um de UBSF, um de UAI e de CAPS de cada distrito sanitário do município, além do CAPS AD e CAPS Infantil.

O caminho escolhido para analisar o corpus se baseia na proposta de análise do discurso influenciada pela perspectiva do construcionismo social (Potter \& Wheterell, 1987; Spink, 2004). A análise de discurso nessa perspectiva enfatiza o processo dialógico e 
performático da linguagem, considerando os conteúdos do discurso como disponíveis socialmente e utilizados conforme os objetivos específicos da conversação. A partir desta proposta, a análise das entrevistas teve os seguintes passos: leitura flutuante e atenta das transcrições das entrevistas, seleção do tópico grupal e identificação dos repertórios interpretativos.

A leitura flutuante e atenta das transcrições das entrevistas abrangeu as entrevistas que abordaram aspectos voltados ao trabalho e participação do psicólogo na saúde pública, como gestão e cotidiano dos serviços, formas de atuação, controle social e compreensão geral sobre o Sistema Único de Saúde. As entrevistas foram transcritas e lidas diversas vezes.

$\mathrm{Na}$ seleção do tópico grupal consideraram-se os momentos das dezoito entrevistas que abordavam as questões e conversas sobre as práticas grupais.

Os repertórios interpretativos são "blocos linguísticos" que as pessoas usam para construir suas versões dos fenômenos em que participam (Burr, 1995; Potter \& Wheterell, 1987). Os repertórios são marcados por termos, metáforas, sinais, figuras de linguagem e imagens utilizados na conversação. Eles não estão locados num nível individual, mas são compartilhados e estão disponíveis como um recurso social. As pessoas os utilizam para justificar alguma versão particular de um evento, para validar, ou questionar os próprios comportamentos, e para manter sua credibilidade na interação (Potter \& Wheterell, 1987). A identificação dos repertórios favorece a possibilidade de categorização, dando maior visibilidade ao processo de produção de sentido.

Este projeto foi aprovado pelo Comitê de Ética da Universidade Federal de Uberlândia sob o número 104/05. Ressaltamos que todos os procedimentos éticos foram respeitados e os nomes utilizados são fictícios.

\section{REPERTÓRIOS INTERPRETATIVOS SOBRE PRÁTICAS GRUPAIS}

Buscando compreender os sentidos das práticas grupais presentes nas entrevistas com psicólogos que atuam em saúde pública, optamos por analisar mais detalhadamente aqueles momentos da entrevista referentes à definição de grupo e também do papel do profissional. Entre os principais repertórios descritos estão: grupo como espaço coletivo, grupo como alternativa para demanda, grupo como proposta mediadora e grupo como estranhamento. A seguir, apresentaremos cada um dos repertórios e suas implicações.

\section{Grupo como espaço coletivo}

Quando analisamos as descrições referentes ao grupo terapêutico, nomeamos o repertório do "grupo como espaço coletivo". É um repertório referente a uma posição genérica e positiva sobre o grupo. Ele é marcado por imagens e palavras relacionadas a troca, socialização, convívio, coletividade, interação e corresponsabilidade. Foi identificado em enunciados que respondem de forma positiva à avaliação do trabalho em grupo, aos objetivos que apresentam e aos aspectos transformadores possibilitados pela prática.

Esse repertório traz possibilidades de uma prática relacionada ao coletivo, à troca e à socialização. Por meio desta troca, o grupo é considerado como uma forma de produzir conscientização, de fazer emergir o conhecimento sobre si e os outros, levando a uma melhora dos participantes. Isso pode ser visualizado nos trechos a seguir:

\begin{abstract}
Busco a própria melhora, a conscientização, né, delas mesmas, é.... da... da condição em que elas se encontram, que elas mesmas podem fazer por elas mesmas (Mariana, UBSF).

O objetivo era resgatar a convivência mesmo, respeito, socializar, sabe.... assim... todas essas questões (...) Ter apoio, troca entre eles. A melhora é mais significativa. (Cecília, UAI).

Decidi trabalhar em grupo eu acho que é pela riqueza, assim, da coletividade, acho que a gente vive coletivamente, né?. E é importante pensar isso no coletivo, né?. (...).eu acho que tem uma contribuição do trabalho de grupo que é essa experiência com o outro, né? (Débora, CAPS).
\end{abstract}

No repertório do grupo como espaço coletivo o papel do psicólogo se relaciona a uma atuação de cuidado pelo grupo que envolve ações como escutar, cuidar, orientar, mediar e fazer psicoterapia. Seguem trechos que ilustram como os profissionais descrevem o seu papel:

\begin{abstract}
Então assim, é um trabalho de escuta e um trabalho em que ele vai poder, um... um espaço onde ele vai poder falar, né falar e se escutar. É um trabalho de psicoterapia comum, né, que você poderia realizar individualmente, mas que ele é realizado em grupo (Márcia, UBSF).
\end{abstract}

Acho que é mediar, um deles acho que é mediar, outro é fazer intervenções 
terapêuticas assim que julgar necessárias (...) é fortalecer, né, esses vínculos entre eles, e cuidar do... da demanda deles, da demanda terapêutica, digamos assim (Michele, CAPS).

É, orientando, né, é tá ouvindo e ao mesmo tempo conduzindo o grupo, né?. Então assim, pra que todos, que, né, pra que o grupo acolha às vezes aquele que tá precisando mais de falar, né?. Então vai revezando, cada um trabalha também de um jeito, né? (Amanda, CAPS).

Estas descrições explicitam o cuidado com o usuário pela intervenção terapêutica; contudo o trabalho grupal descrito por meio deste repertório se traduz de forma genérica, não se explicitando as nuanças da intervenção do profissional nem o trabalho a ser realizado pelo psicólogo para que o grupo se efetive como promotor de um espaço de cuidado e mudança.

Neste repertório interpretativo, o grupo é descrito como potencial, mas ainda sem ser problematizado e praticado como uma construção conjunta, na qual tanto o terapeuta e os participantes são ativos no processo. As falas remetem o grupo a um contexto de atuação do profissional e pouco se exprime sobre a ação e a contribuição do usuário, que é posicionado de forma passiva.

Entendemos que o uso dessas imagens e palavras pode estar relacionado à maneira como esses profissionais vêm se aproximando da prática grupal, para dar sentido ao que anteriormente não era uma atuação habitual no que concerne à formação e inserção da Psicologia no contexto de saúde pública e à demanda por terapias de grupo. Trata-se, contudo, de um repertório favorecedor das práticas grupais neste contexto.

\section{Grupo como alternativa para a demanda}

Outro repertório presente nas entrevistas foi o do "grupo como alternativa para a demanda". Trata-se de um repertório muito comum, utilizado para justificar a adoção das práticas grupais por um viés econômico e administrativo. $\mathrm{O}$ grupo constitui uma resposta a uma exigência do sistema público, que não tem condições de oferecer atendimento individual a todos que procuram o serviço. Este repertório traz imagens e palavras relacionadas a: atender demanda, serviço público, alternativa, formação em saúde pública.

Esse repertório é utilizado durante a entrevista, na maioria das vezes, em enunciados que respondem ao porquê de haverem decidido trabalhar em grupo, ou ainda quando os entrevistados apontam as dificuldades de atuar no grupo, além da própria definição que constroem sobre ele.

Podemos observar o lugar reservado ao grupo neste repertório nos seguintes trechos:

Fui me formando nas propostas da saúde pública, fiz treinamento em relação a atendimento de grupo. Existia essa proposta, numa demanda tão grande não poderia realizar um trabalho individualizado, nem mesmo que tivesse a mesma característica da referência médica, em função de uma demanda muito grande. O grupo é uma outra alternativa: tem grupo terapêutico, grupos operativos e oficinas terapêuticas, dentro dessa necessidade (Beatriz, UBS).

Não foi nenhuma decisão, o serviço te leva a fazer isso, a pensar de outro jeito. É o meu desejo interno mesmo, gosto de trabalhar com grupo. Acho produtivo, acho que é possivel, te coloca a pensar muito, a repensar muito (Amanda, CAPS.)

Não lembro, acho que faz parte de mim. Comecei com grupo de criança, muito pela demanda que pressionava. Hoje a gente entende muito a questão de tá junto mesmo, aprender a conviver, de respeitar o outro, de abrir escuta, de falar, de confiar. Acho a melhor modalidade de trabalho que tem (Cecília, UAI).

Estes trechos marcam o processo de produção de sentidos sobre a prática grupal a partir do repertório do "grupo como alternativa para demanda". A resposta à pergunta "Por que decidiu trabalhar com grupos?" mostra um posicionamento que envolve a demanda inicial da instituição e sua história como profissional. Assim, temos a produção de justificativas que parecem tentar promover sentidos mais positivos diante de uma necessidade e exigência do contexto de trabalho.

Essa estratégia discursiva descreve o profissional não apenas como sensível às necessidades e especificidades da saúde pública, mas como alguém que se apropriou da proposta do serviço, fazendo-a sua também. Não obstante, tal apropriação é acompanhada por argumentos que naturalizam a adoção da prática grupal, sendo marcada pelas ideias de um processo inevitável de formação no qual o entrevistado "fui [foi] me [se] formando", "não foi nenhuma decisão", até culminar na imagem que a prática grupal "faz parte de mim".

Este processo de formação profissional e atenção à demanda está associado a uma crítica à formação 
universitária, que não prepara os psicólogos para promover ações resolutivas ante a demanda do serviço público de saúde. No trecho a seguir, em que o profissional responde à pergunta "Por que decidiu trabalhar em grupo?", este aspecto é ressaltado:

\begin{abstract}
Porque a demanda é muito grande. A universidade forma pro atendimento individual e na saúde pública nem sempre o atendimento individual é possível. Alguns casos torna-se necessário em função da patologia, em outros é possível colocar as pessoas em grupos, trabalhar com elas essas dificuldades. Acho que é até um trabalho prazeroso, muito gostoso. (Mariana, UBSF).
\end{abstract}

O repertório do grupo como alternativa para a demanda coloca o psicólogo como alguém que não foi preparado para a atuação na saúde pública e precisa de capacitação, ainda que se comprometa com essa proposta terapêutica e com os desafios do trabalho neste contexto.

Trata-se de um repertório que legitima a prática grupal e marca a integração do psicólogo no contexto de saúde pública; porém tal legitimação e integração não se dão em um processo marcado pela reflexão crítica e transformadora das ações e dos profissionais que as realizam.

\section{Grupo como proposta mediadora}

Este repertório sobre a prática grupal está relacionado, especialmente, ao processo de produção de sentidos sobre as oficinas. É um repertório que distingue a oficina de outras práticas grupais, dandolhe especificidade e densidade. A oficina, por utilizarse de técnicas não verbais e da construção de objetos, é descrita como se exercesse uma função mediadora do sujeito consigo próprio e com os outros que o rodeiam. O repertório "grupo como proposta mediadora" é caracterizado por imagens e palavras relacionadas a: instrumento, produto, melhora manual, descobrir habilidades, colocar sentimentos, expressão, inserção. Nele, o grupo é identificado ao objeto mediador, mantendo a tensão entre produto e sujeitos e destes entre si.

Este repertório interpretativo é utilizado pelos profissionais nos relatos sobre as oficinas no que diz respeito aos objetivos, ao modo de compor os grupos e a definições de oficina. O uso desse repertório busca qualificar o grupo como uma prática alternativa que promove a produção de algo cujo efeito é terapêutico. É uma descrição de prática grupal referida, predominantemente, ao atendimento ao psicótico, a qual favorece a construção de um produto e promove o desenvolvimento de habilidades, a organização pessoal e a melhora dos participantes. Neste sentido, o psicólogo busca conduzir o grupo por meio de algum material que componha a atividade, ficando atento à descoberta de habilidades e à "mediação" do que é produzido. A seguir, apresentamos alguns trechos nos quais está presente o repertório do grupo como proposta mediadora.

As oficinas têm objetivo de fazer uma mediação, através do instrumento que você usa, seja a dança, a música, a pintura, a história. É você tentar fazer uma mediação. No caso de transtornos mentais graves, o que a gente percebe que às vezes falha muito é essa amarração simbólica mesmo das coisas (Débora, CAPS).

Possibilitar inserção do paciente psicótico, atividade que o tirasse de casa, que tivesse outra proposta que não só estar consigo ou familiares, de que o paciente tivesse práticas alternativas, não só a consulta psiquiátrica e $o$ atendimento psicológico; desenvolver também um trabalho, não tivesse que ter um produto, mas tinha também essa ideia pelo investimento de material (Beatriz, UBS).

Olha, eu aprendi que oficina era uma coisa pra fazer, né, pra fazer na prática alguma coisa, algum trabalho (Cristina, UAI).

Então, quando a gente busca oficina, é muito de acreditar, né, que o trabalho manual ele melhora as pessoas em vários aspectos (Clara, CAPS).

O uso desse repertório interpretativo produz, muitas vezes, uma contraposição entre a oficina e o grupo terapêutico, como se estes fossem dois pólos do contínuo grupal. Esta comparação entre a oficina e o grupo tem a função de aproximar as duas práticas, ao mesmo tempo em que aponta para os diferentes funcionamentos que elas promovem, definido o grupo como uma prática da psicoterapia, de "concentração", e a oficina como um modo de ensinar, descobrir habilidades, estar junto mais livremente e promover a auto-estima.

[Os objetivos dos grupos terapêuticos?] Troca entre usuários, psicoterapia em si mesmo, tratamento do que o usuário traz, fortalecer esses vínculos entre eles, cuidar da demanda deles, da demanda terapêutica (Michele, CAPS).

[Objetivos oficinas?] Troca também, porque não tem aqui oficineiros que vão ensinar, a 
gente atua nesse sentido de ensinar. $O$ objetivo é descobrir as habilidades. Questão da autoestima, também. Falam: "não dou conta de nada", aí tem um trabalho pronto: "Nossa, eu fiz isso". Valor da autoestima é grande nessa oficina, também capacidade de ensinar ao outro; se sentem muito valorizados com isso (Michele, CAPS).

[Composição dos grupos?] Oficinas é mesclado: pacientes ficam junto, não separa psicótico do neurótico grave, fica todo mundo junto. O espaço oficina é o espaço livre: entra, fuma, sai, toma água, deita um pouquinho, depois volta; já o espaço do grupo é de concentração (Amanda, CAPS).

Estas comparações também fazem aparecer distinções no papel do psicólogo na oficina e no grupo terapêutico. No grupo, a função de cuidado é um desdobramento do que é feito na terapia individual; já na oficina, o papel do "saber fazer" coloca o psicólogo no papel de ensinar um fazer e mediar o terapêutico pela produção.

As relações entre estas duas práticas grupais produzidas pelo uso deste repertório podem ser percebidas também nos termos utilizados para nomeálas: grupo e oficina. O primeiro dispensa o termo terapêutico, como se ele fosse evidente, sendo redundante repeti-lo; o segundo produz um apagamento do termo grupo, ocultando o processo grupal produzido nas interações dos participantes durante as oficinas. Estes termos promovem deslizamentos que podem levar a uma relação de hierarquia entre as práticas, colocando a oficina em um patamar inferior como instrumento terapêutico e como produtora de novas subjetividades. Este modo de realizar tais comparações pode despotencializar a prática grupal, ameaçando a inteligibilidade e produtividade da oficina e do grupo terapêutico.

\section{O grupo como estranhamento}

Esse repertório é nomeado "grupo como estranhamento" por apontar as dúvidas, receios e despreparos dos psicólogos em relação a essa prática. É acompanhado de imagens e palavras como não terapêutico, necessidade do instrutor, risco da tarefa, atendimento individual. Esse repertório está presente quando os profissionais respondem sobre como avaliam os grupos (sejam terapêuticos, operativos, oficinas ou outros), quais seus objetivos, suas dificuldades, bem como o papel por eles desempenhado nesse contexto.

Ele é utilizado na construção de dois estranhamentos: a) em relação ao atendimento de "várias pessoas ao mesmo tempo", ou seja, em contraposição ao atendimento individual; e b) em relação à atuação pautada por uma atividade artística/artesanal.

O repertório do "grupo como estranhamento" se constitui em relação ao atendimento individual à medida que gera um conflito quando compara as duas modalidades de atuação; e o atendimento individual é tido, então, como superior, produzindo melhores efeitos e sendo considerado o atendimento de preferência, conforme observamos no trecho a seguir:

\begin{abstract}
Assim, se eu me sentiria mais confortável de poder oferecer um trabalho individual, isso aí não há a menor dúvida, eu penso que renderia mais, né, assim, mexeria mais com eles, né, o êxito seria melhor do que no grupo. Mas assim... tem tido resultados interessantes, tenho tido resultado bons no sentido do alívio dos sintomas, né, da melhora do comportamento (Márcia, UBSF).
\end{abstract}

A atuação em grupo, conforme descrita por este repertório, traz dificuldades para os psicólogos e usuários. O profissional, apesar de considerar o grupo como uma proposta útil, acha que ele demanda esforços de convencimento do usuário, conforme dois trechos de entrevista de uma mesma psicóloga:

[Qual sua avaliação do grupo terapêutico?] $A$ maioria tem dito que tem sido bom. Acho que é uma abertura legal, porque a gente não consegue atender todos individualmente. Impossível. [Gostaria de atender mais individual?] Não, penso que grupo ajuda muito. Tem casos precisam ser individuais sim. Hoje a gente tem tentado o máximo que a gente pode no grupo. As pessoas falam: "Ah, mas aquilo não dá pra falar no grupo", então a gente fala: 'Ah, vamos pro grupo, quem sabe dá' (Amanda, CAPS).

Os problemas encontrados na atuação em grupo constroem o papel do psicólogo a partir de termos como "muita gente", "ligar uma coisa com a outra", "trabalho maior", "resistência", "conduzir as diferenças" e "conflito". Este repertório constrói a intervenção grupal como uma prática "sobrecarregada" tanto em relação ao número de participantes quanto no tocante às dificuldades que a acompanham.

Há dificuldade também... assim de que são... é muita gente, né, é ao mesmo tempo, né, então você tá atenta a uma coisa, a outra. Pra você ligar uma coisa com a outra é um 
trabalho maior, assim, nesse sentido (Michele, CAPS).

Eu acho que tem essa resistência em falar de questões pessoais, né, às vezes tem... tem situações que a gente precisa ouvir fora (...). Acho que a dificuldade maior é essa, de saber conduzir as diferenças. Às vezes pode surgir conflito, né, como que você vai manejar isso, né, sem que você também abafe a situação, porque tem que aparecer (Débora, CAPS).

Já em relação à atuação pautada por uma atividade artística/artesanal, o repertório do grupo como estranhamento destaca uma tensão entre ouvir e produzir. Nas oficinas, o estranhamento está ligado à ideia do exercício de uma tarefa em que a fala do participante não ocupa um lugar central. Esta ideia é apresentada com certo desconforto pelos profissionais, pelo receio da perda do que consideram terapêutico. A atuação, desta forma, é descrita como marcada pela insegurança, em que a qualquer momento o sentido do terapêutico está em risco. Este repertório é usado desta maneira, muitas vezes, quando o profissional responde acerca da avaliação dos usuários sobre a oficina:

\section{Eles gostam muito, a oficina é requisitada, mas tem que tomar muito cuidado pra não ficar um fazer pelo fazer; tá chamando, tá buscando, senão, fica muito a questão tarefeira. Tem que tá sempre prestando atenção, se tá virando uma tarefa ou se tá tendo um sentido terapêutico (Michele, CAPS).}

$\mathrm{Na}$ descrição da oficina, o repertório do "grupo como estranhamento" também se faz presente ao considerá-la como uma prática na qual não se enfatiza a função de interpretação. Tal repertório marca uma confusão quanto ao papel desses profissionais na oficina, os quais ficam divididos entre escutar, compor uma atividade, observar, ficar juntos e participar, colocando em questão qual é sua função como terapeuta e qual a razão dessa prática para a melhora do usuário. Novamente, associado a isso, há um questionamento da produtividade $\mathrm{e}$ da função terapêutica desta prática, bem como do papel do psicólogo.

Eu acho que é um instrumento... assim... um dispositivo que a gente tem precisado repensar mesmo, (...) tem pessoas que consideram que é terapêutico, né, e tem pessoas que às vezes acham que não é terapêutico o que a gente faz na oficina, né.
Então eu penso assim: bom, se não é terapêutico é porque não está sendo terapêutico; mas deveria ser, né, deveria ter um efeito (Débora, CAPS).

Fiquei algumas vezes achando que não produzia nada (risos), foi um sentimento começando um trabalho com psicótico. Mas depois isso foi diluindo; considero não a expectativa que eu tenho, aquilo já era muito. Pra mim é muito satisfatório o vínculo. Agora na questão de uma produção, não tinha uma produção pra consumo, que a gente faz bazar. (...) Gosto dos [grupos] específicos da saúde mental. (...) tenho preferência pelos grupos terapêuticos. Vou bem no grupo de orientação, porque acho que ele é terapêutico, vou bem na oficina terapêutica até onde sinto que tenho algo a acrescentar. Tenho dificuldade nas oficinas de não ficar só na proposta da produção. A gente cobrava tanto ter um instrutor nesse grupo, pra gente poder ficar mais livre dessa tarefa na oficina. Mas eu gosto de estar na oficina (Beatriz, UBS).

A descrição da oficina a partir do repertório do grupo como estranhamento está marcada por certa dificuldade em significar o papel do psicólogo, pelo redimensionamento da fala e da interpretação, bem como da prática mediada pelo ocupacional e do trabalho como instrutor. Já em relação ao grupo terapêutico/operativo, no qual há espaço para fala e interpretação, o estranhamento se dá pela presença de vários participantes, em comparação com $\mathrm{o}$ atendimento individual.

Nesse sentido, o repertório do "grupo como estranhamento" está presente tanto na descrição da oficina quanto na de outras práticas grupais, com ênfases distintas, mas que podem prejudicar a atuação, dada a dificuldade apresentada pelos profissionais em considerar diversamente o terapêutico.

\section{Para além do viés individualista}

A análise realizada concorda com o apresentado na literatura (Bezerra, 1987; Molena, 1992; Souza, 1999) quanto às dificuldades e desafios presentes nas práticas grupais no contexto de saúde pública, no que se refere à permanência da clínica tradicional, às falhas presentes na formação inicial e aos conflitos de pensar o grupo para além da demanda e tomá-lo criticamente como ferramenta na prática em saúde.

Os repertórios interpretativos identificados, em sua maioria, permitem legitimar a prática grupal de diferentes maneiras, seja porque que ela pode produzir, de forma coletiva, efeitos benéficos aos seus 
participantes, seja porque responde às necessidades de atendimento do serviço, seja ainda por se constituir como uma alternativa complementar do tratamento. Contudo, cada um dos repertórios disponíveis aponta também para um desafio a ser superado no exercício crítico dessa forma de prática psicológica. Assim, o repertório do "grupo como espaço coletivo" explicita a necessidade de pensar o grupo como construção ativa da qual participem usuários e outros profissionais da equipe. O repertório do "grupo como alternativa para a demanda" mostra como a atuação do psicólogo, muitas vezes, é marcada por uma integração ao sistema público que se dá de forma a reproduzi-lo sem questionamentos.

Já o repertório do "grupo como proposta mediadora" traz uma hierarquia entre diferentes formas da intervenção grupal, comprometendo a qualidade e a potencialidade desta forma de trabalho. O repertório do "grupo como estranhamento" expande a tensão presente no repertório anterior, questionando a legitimidade da prática grupal, numa relutância em reconhecer o terapêutico em práticas que se distanciam do setting individual, baseado na conversação, e nas quais a intervenção técnica se dá pela escuta e interpretação.

Este viés clínico-individual sustentado pelo discurso da psicoterapia individual está presente na constituição de todos os repertórios identificados nesta pesquisa, produzindo algumas ausências na descrição das práticas grupais. Desta forma, tais repertórios não contemplam as ações voltadas aos grupos, organizações, equipes e comunidades, estando seu foco na prática grupal como uma intervenção voltada ao cuidado do indivíduo.

Nesse mesmo sentido, com exceção das descrições sobre a oficina feitas pelos profissionais de CAPS, não há uma diferenciação no uso dos repertórios conforme o nível de atenção no qual estão inseridos os psicólogos entrevistados, produzindo uma descrição do grupo como prática genérica, segundo um modelo abstrato e único. Essa característica mostra que os repertórios são compartilhados pelos profissionais e utilizados segundo objetivos específicos na conversação, não estando determinados pelo tipo de instituição no qual os psicólogos desenvolvem seu trabalho

É necessário, assim, rever a formação profissional para a prática grupal, buscando-se uma análise crítica do uso destes repertórios disponíveis e reconhecendose seus limites. Uma maior sensibilidade ao contexto de utilização das intervenções grupais pode ampliar suas formas de construção, dando especificidade a cada uma delas e delimitando suas contribuições.
Da mesma forma, cabe aos psicólogos construírem, coletivamente, espaços de articulação, produção e intervenção de novas maneiras de dizer e fazer a prática grupal no contexto de saúde brasileiro, ampliando suas possibilidades de transformação no cuidado de pessoas, comunidades, equipes e serviços de saúde.

\section{REFERÊNCIAS}

Benevides, R. (2005). A psicologia e o sistema único de saúde: quais interfaces? Psicologia e Sociedade, 17(2), 21-25.

Bezerra Jr., B. (1987). Considerações sobre terapêuticas ambulatoriais em saúde mental. Em S. A. Tundis \& N. R. Costa (Org.), Cidadania e Loucura - políticas de saúde mental no Brasil (pp. 133-169). Petrópolis: Vozes-Abrasco.

Bock, A. M. B. A. (Org.). (2003). Psicologia e o Compromisso Social. (1a ed.). São Paulo: Cortez Editora.

Burr, V. (1995). What does it mean to be a person? In Burr, V. An Introduction to Social Constructionism (pp. 125-139). New York: Routledge.

Dimenstein, M. D. B. (2000). A Cultura Profissional do Psicólogo e o Ideário Individualista: Implicações para a Prática no Campo da Assistência Pública à Saúde. Estudos de Psicologia, 5(1), 95-121.

Goya, A. C. A., Rasera, E. F. (2007). A Atuação do psicólogo nos Serviços Públicos de Atenção Primária à Saúde em UberlândiaMG. Horizonte Científico. 7. Recuperado em 07 de junho de $2008 \mathrm{em}$ http://www.horizontecientifico.propp.ufu.br/

Lancetti, A. (1993). Clínica Grupal com Psicóticos: a grupalidade que os especialistas não entendem. Em A. Lancetti (org), Saúde e Loucura Grupos e Coletivos (pp.155-171). São Paulo: Hucitec.

Lo Bianco, A. C, Bastos, A. V. B, Nunes, M. L. T \& Silva, R. C. (1994). Concepções e Atividades Emergentes na Psicologia Clínica: Implicações para a formação. Em Conselho Federal de Psicologia (org), Psicólogo Brasileiro: Práticas Emergentes $e$ Desafios da Formação (pp.7-79). São Paulo: Casa do Psicólogo.

Martins, S. T. F. (2003). Processo grupal e a questão do poder em Martín-Baró. Psicologia e Sociedade, 15(1), 201-217.

Molena, C. (1999). O Psicólogo nos Serviços Públicos de Saúde: Concepções sobre Grupo. Monografia de Conclusão de Curso em Bacharel de Psicologia. Faculdade de Filosofia, Ciências e Letras de Ribeirão Preto, Universidade de São Paulo, Ribeirão Preto.

Nascimento, M. L., Manzini, J. M. \& Bocco, F. (2006). Reinventando as Práticas Psi. Psicologia e Sociedade, 18(1), 15-20.

Potter, J. \& Wetherell, M. (1987). Discourse and Social Psychology. Londres: Sage.

Secretaria Municipal de Saúde de Uberlândia. (2005). Mais Saúde: Informativo da Saúde Mental. Uberlândia: Secretaria Municipal de Saúde.

Silva, R. C. (1992). A Formação em Psicologia para o trabalho na Saúde Pública. :Em F. C. B. Campos (Org), Psicologia e Saúde: repensando práticas (pp.26-57). São Paulo: Hucitec.

Souza, P. G. (1999). Dialogando com Psicólogos de Serviços Públicos de Saúde: Um Olhar Sobre o papel do Coordenador. Monografia de Conclusão de Curso em Bacharel de Psicologia. 
Faculdade de Filosofia, Ciências e Letras de Ribeirão Preto, Universidade de São Paulo, Ribeirão Preto.

Spink, M. J. (org). (2004). Práticas discursivas e produção de sentidos no cotidiano: aproximações teóricas e metodológicas (3a. ed.). São Paulo: Cortez.

Spink, M. J. P., Bernardes, J. \& Menegon, V. S. M. (2006). A Psicologia em diálogo com o SUS: Prática Profissional e
Produção Acadêmica. São Paulo: Associação Brasileira de Ensino de Psicologia e Ministério da Saúde.

Recebido em 24/07/2008 Aceito em 08/10/2009

Endereço para correspondência:

Emerson Fernando Rasera. Avenida Pará, 1720, Campus Umuarama, Bloco 2C, Sala 2C47, CEP 38400-902, Uberlândia-MG, Brasil.E-mail: emersonrasera@uol.com.br. 